\title{
Unmanned Aerial Vehicle (UAV) Photogrammetry Produces Accurate High-resolution Orthophotos, Point Clouds and Surface Models for Mapping Wetlands
}

\author{
Marinus Axel Boon ${ }^{1}$, Richard Greenfield ${ }^{1}$, Solomon Tesfamichael ${ }^{2}$ \\ ${ }^{1}$ Department of Zoology, University of Johannesburg, Auckland Park, 2006, South Africa, \\ boon@live.co.za \\ ${ }^{2}$ Department of Geography, Environmental Management and Energy Studies, University of \\ Johannesburg, Auckland Park, 2006, South Africa
}

http://dx.doi.org/10.4314/sajg.v5i2.7

\begin{abstract}
Unmanned Aerial Vehicle (UAV) photogrammetry has recently become a powerful tool that offers a viable alternative to traditional remote sensing systems, particularly for applications covering relatively small spatial extents. This paper presents results of a study that aimed at investigating the use of UAV photogrammetry as a tool for the mapping of wetlands. A multi-rotor $U A V$ and a digital camera on a motion compensated gimbal mount were utilised for the survey. The survey of the 100ha study area at the Kameelzynkraal farm, Gauteng Province, South Africa took about 21/2 hours and the generation of the point cloud about 18 hours. Ground control points (GCPs) were positioned across the site to achieve geometrical precision and georeferencing accuracy. Structure from Motion (SfM) computer vision techniques were used to reconstruct the camera positions, terrain features and to derive ultra-high resolution point clouds, orthophotos and 3D models from the multi-view photos. The results of the geometric accuracy of the data based on the 20 GCPs were $0.018 m$ for the overall and $0.0025 m$ for the vertical root mean squared error (RMSE). The results exceeded our expectations and provided valuable, rapid and accurate mapping of wetlands that can be used for wetland studies and thereby support and enhance associated decision making to secure our future.
\end{abstract}

\section{Introduction}

The advent of photogrammetry using UAV has proved a cost effective and efficient alternative to traditional remote sensing techniques (Shabazi et al., 2014). The technology has been applied successfully for mining (Peterman and Mesarič, 2012), ecological applications (Anderson and Gatson, 2013) and other constantly changing environments such as rivers (Rathinam et al., 2007, Ahmad et al., 2013, Flener et al., 2013, Ouédraogo et al., 2014). UAV photography can provide high spatial details needed by scientists (Li et al., 2010, Shahbazi et al., 2014) and is not constrained by orbital times or flight schedules (Zweig et al., 2015). Progress in computer vision and computing power has led to the advancement of UAV photogrammetry. This includes key 
advancements such as operational solutions for 3D data acquisition based on Structure-fromMotion (SfM) photogrammetry and multi-view stereo (MVS) (James and Robson 2012, Westoby et al., 2012, Fonstad et al., 2013). James and Robson (2012) studied the straight forward reconstruction of three-dimensional (3D) surfaces and topography with a camera and achieved a general accuracy of centimeter-level precision. Westoby et al., (2012) achieved decimeter-scale vertical accuracy. The use of computer vision software is an alternative technique to create $3 \mathrm{D}$ models from photographs that evolved considerably in recent years. This alternative is a cost effective and easy to use method compared to expensive laser scanners or rigorous photogrammetry. The technique also only requires a few control measurements and the processing is automated. Computer vision software integrates state-of-the-art SfM and MVS algorithms to generate/reconstruct very dense and accurate point clouds from a series of overlapping photographs as indicated in Verhoeven, (2011), James and Robson, (2012) and Westoby et al., (2012). UAV photogrammetry can generate high resolution digital elevation models (DEMs) which are amongst the most important spatial information tools to investigate geomorphology and hydrology (Ouédraogo et al., 2014). The accurate 3D measurement including volume determination from UAV data for erosion gullies was successfully completed in a study by Stöcker et al., (2015). Complex wetland vegetation information at a community scale can be identified (Li et al., 2010, Lechner et al., 2012), delineated and classified (Marcaccio et al., 2015, Zweig et al., 2015) through high resolution orthophotos acquired using UAVs.

The importance of UAVs has grown considerably over the last years with rising application thereof in research. The number of Unmanned Aerial Systems (UAS) referenced in the 2013 annual inventory of Unmanned Vehicle Systems (UVS) International (van Blyenburg, 2013 cited by Colmina and Molina, 2014) indicates a gradual rise in research applications. The study by Shahbazi et al., (2014) indicated a considerable increase in the use of UAV imagery for research in the agricultural and the natural environment. The applications of the reviewed articles included five principal fields: precision agriculture and rangeland monitoring, natural disaster management, aquatic ecosystem management, polar remote sensing and wildlife research. However, wetlands present a different challenge to remote sensing application compared to other ecosystems that have received a great deal of attention in the remote sensing community. The interface of wetlands between terrestrial and aquatic environments makes it difficult to examine and understand (Ellery et al., 2009) these ecosystems. This paper assessed the use of UAV photogrammetry as a tool for accurate mapping of wetland ecosystems. Such a study paves the way for comprehensive studies that ultimately support informed decision making.

\section{Study Area}

The study area is located on the Kameelzynkraal farm to the east of Pretoria in the Kungwini Local Municipal area, Gauteng Province, South Africa. The 100ha wetland study area spans just over $1 \mathrm{~km}$, starting just below an earthen dam on the south western boundary of the Cors-Air 
model aircraft airfield east of the R25 road, just south of the M6 intersection, up until to the dam wall of another earthen dam on a neighbouring farm in a north eastern direction (Figure 1). The Cors-Air study area can be described as a channelled valley-bottom wetland system. Large sections of the wetland were transformed due to infilling, agriculture, sand mining, excavation of trenches/drains, construction of roads, infrastructure and earthen dams. The system still represents typical characteristics of a wetland such as wetland soils and vegetation. The known water source of the wetland is surface runoff from the catchment stretching just over $2 \mathrm{~km}$ upstream, lateral surface inputs and fountains.

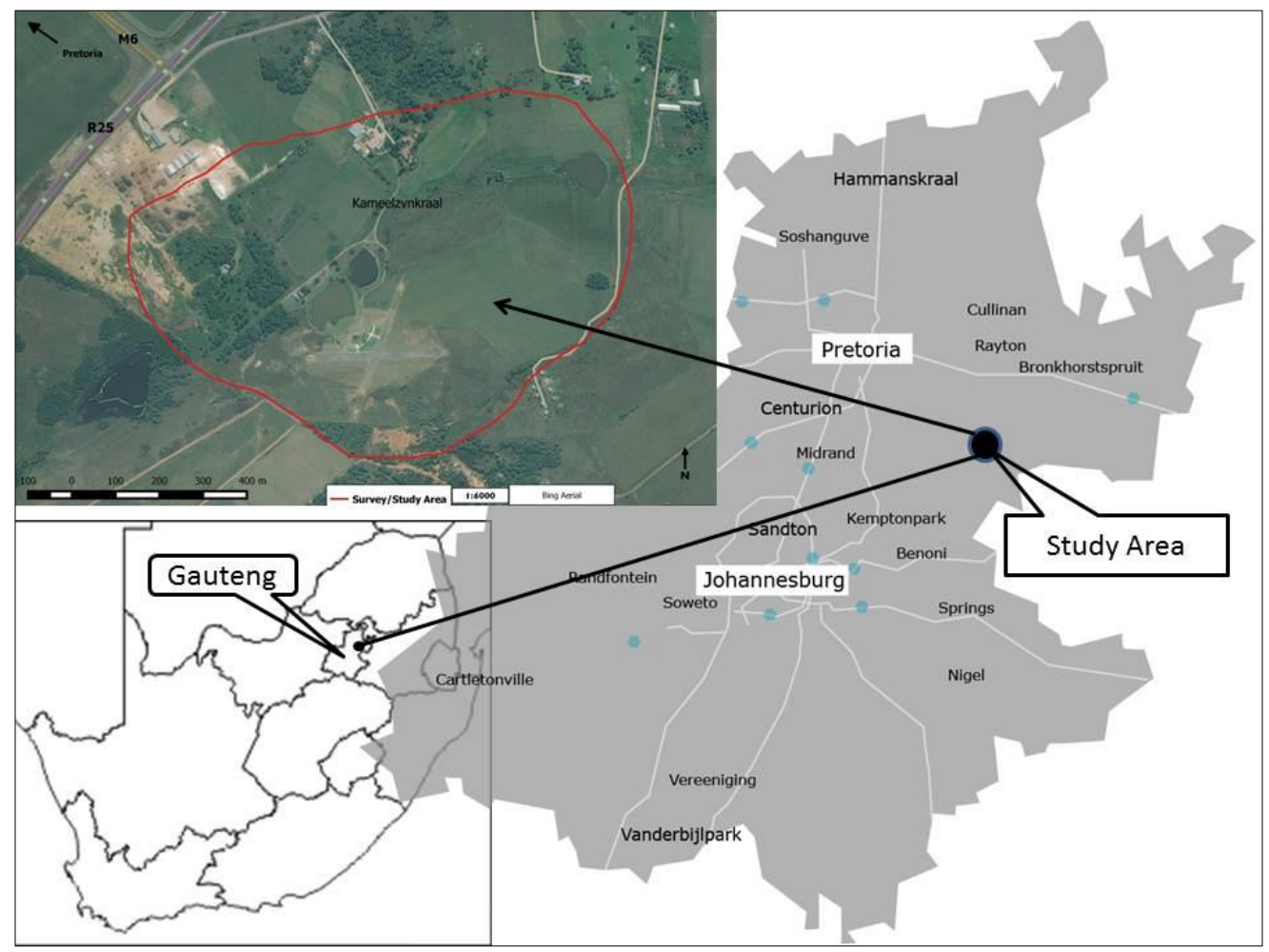

Figure 1. The Cors-Air study area to the east of Pretoria, Gauteng Province

\section{Materials and Methods}

The methodology can be divided into four phases indicated in Figure 2 and discussed in sections 3.1 to 3.4 . 


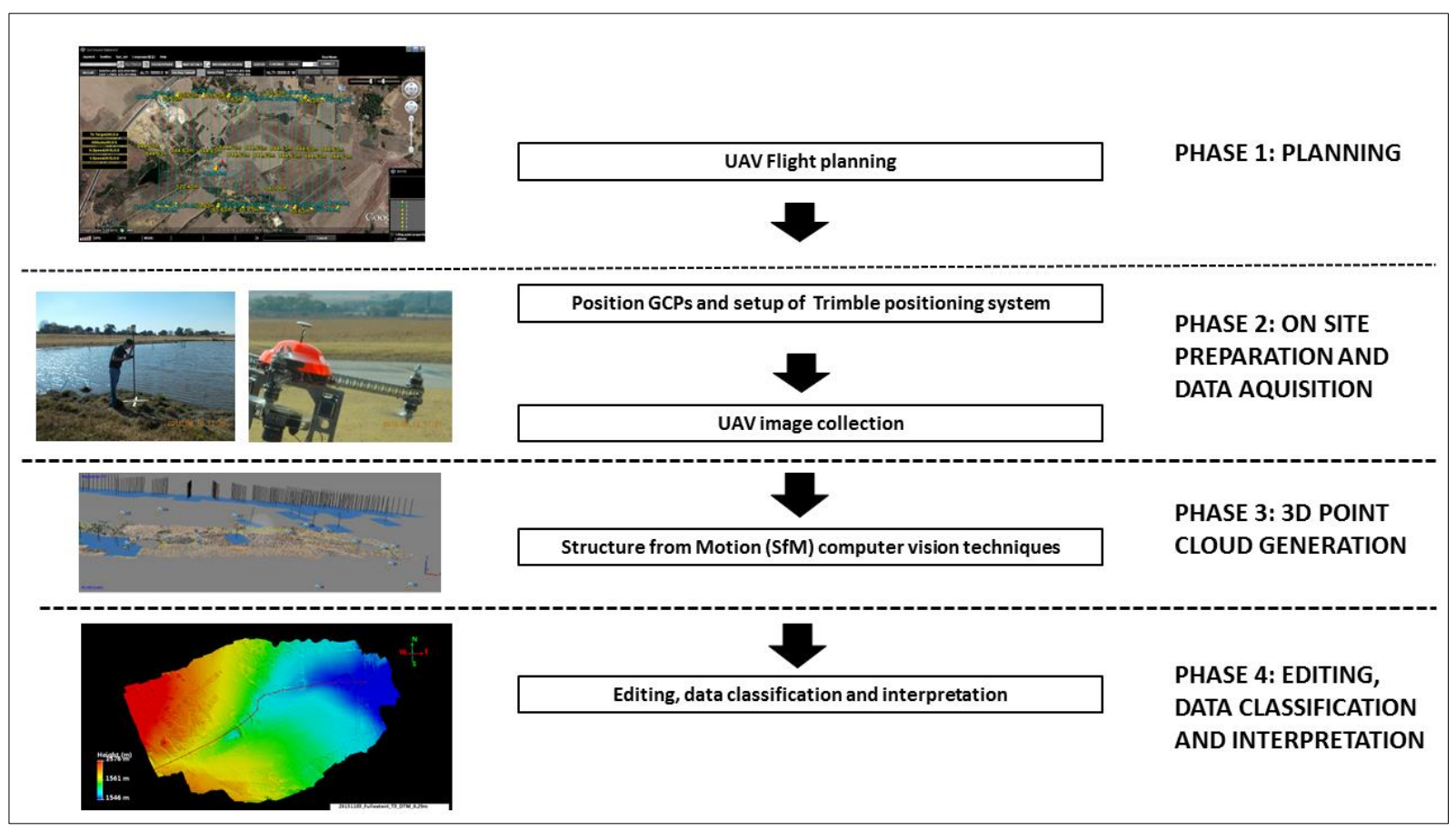

Figure 2. Flow diagram of methodology

\subsection{UAV Flight Planning}

This phase included calculation of study area, number of strips required, photo scale, flying height and percentage of overlapping and preparation of the final flight plan. A 100ha UAV survey area was selected to include an entire functional wetland area including the adjacent slopes in order to capture the landscape setting and impacts from the adjacent land uses. The UAV flight lines (number of strips) were spaced between $60-70 \mathrm{~m}$ apart which equated to an $80 \%$ forward overlap and a $60 \%$ side overlap to ensure accurate 3D model reconstruction (Agisoft LLC, 2014). A further motivation was to ensure that the study area was sufficiently surveyed although it is possible to complete the survey with a lower overlap ratio. The ground coverage of a single image equated to $120 \mathrm{x} 80 \mathrm{~m}$. The flying height determined for the UAV survey was $120 \mathrm{~m}$ above ground level (AGL) which is the legal requirement in terms of the Civil Aviation Authority (CAA) and this ensured rapid acquisition of images with a sufficient level of detail of the study area which also equates to a lower cost. A Nikon D3200 (28mm) digital camera was used for the UAV survey to collect 20 megapixel resolution photographs. Camera focal length was set to "Infinity Focus" and the shutter speed to $1 / 800 \mathrm{~s}$. The camera captured images with an approximate ground resolution of $2 \mathrm{~cm}$ per pixel.

\subsection{On Site Preparation and Data Acquisition}

A Trimble (SPS985 GNSS GPS) site positioning system was set up on site and referenced (Hart94 format) with the two nearest national trigonometrical beacons. Ground control points (GCPs) were then positioned across the site and at the boundaries of the UAV survey area (red 
line in Figure 3) including next to the watercourse (Figure 3) at different elevations (20 GCPs spaced over the 100ha) to achieve geometrical precision and georeferencing accuracy. The XYZ location of each GCP marker was determined using the Trimble GPS.

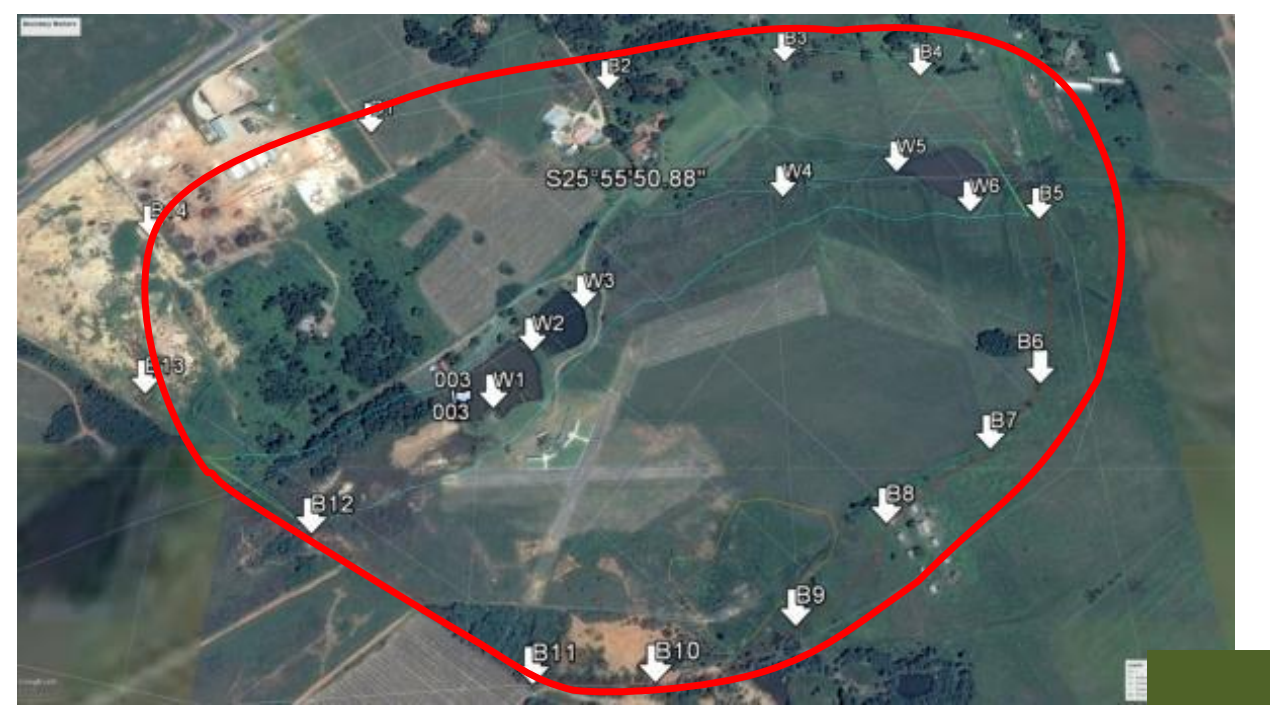

Figure 3. Ground control markers (arrows) positioned at the boundaries of the UAV survey area/study area (red line) including next to the watercourse at different elevations

The UAV images of the study area were collected within 21/2 hours with an AKS Y-6 MKII multi-rotor UAV and the digital camera on a motion compensated gimbal mount. The UAV was equipped with autopilot and navigation-grade GPS. The camera took a photograph every 1-2s, triggered by the on-board flight controller. An on-board GPS was used to record the flight path which was synchronised with the camera before the flight. The flight was undertaken in autopilot mode with a live radio link which allowed real-time position information. Approximately 1200 photographs were captured to cover the study area. The photographs were then visually assessed on the basis of quality, viewing angle including overlap in order to remove any blurred and under or over-exposed images from further processing and analysis. Approximate coordinates were then assigned to the photographs based on the synchronised GPS flight path. The georeferecing results were then inspected for the adequacy of the completed flight lines, image overlap and approximate coordinates before leaving the study area. For more information on UAV setups refer to Colmina and Molina (2014).

\subsection{D Point Cloud Generation}

The completely automated computer vision SfM pipeline provided by Agisoft PhotoScan Professional Version 1.1 commercial software package was used. PhotoScan requires an input consisting of a set of images and then going automatically through the steps of feature identification, matching and bundle adjustment to reconstruct the camera positions (Figure 4) and terrain features. Verhoeven (2011) describes the Photoscan SfM procedure and commonly 
used parameters in detail. A sparse point cloud was created (Figure 4) from 989 images through this initial bundle adjustment. This sparse point cloud included the position and orientation of each camera station and the XYZ/3D coordinates of all image features. The GCPs determined with the Trimble were then imported into PhotoScan after the geographical format was converted into latitude and longitude. The photos in this model were used to identify the 20 GCPs and recompute bundle adjustment to achieve geometrical precision and georeferencing accuracy.
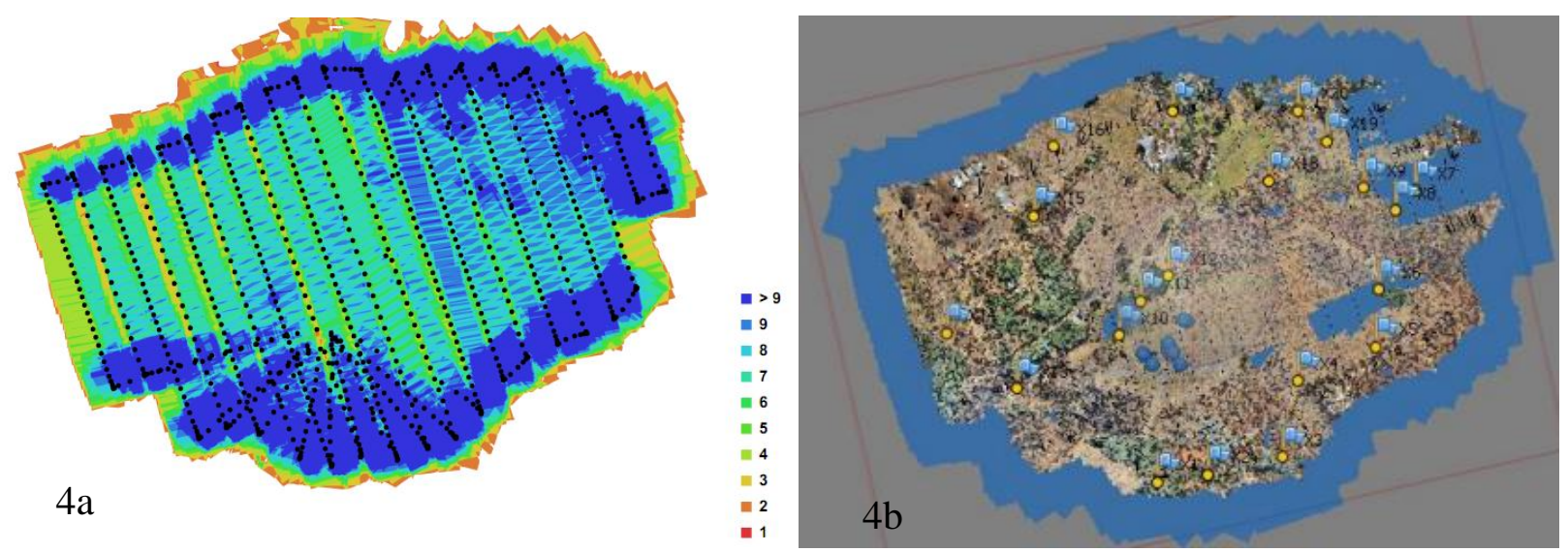

Figure 4. 4a Camera positions and image overlaps. The legend on the right represents the number of images in which a point appears. $4 \mathrm{~b}$ Sparse point cloud with an overlay of ground control points/markers

A dense point cloud set to high quality was then built based on multi-view stereopsis (MVS) for the full study extent. Higher quality settings are used to obtain more detailed and accurate geometry, but require longer time for processing (Agisoft LLC, 2014). Dense point clouds were also built in high reconstruction quality for a smaller spatial extent which covered the wetland area (42 ha/248 images) and low reconstruction quality for the full extent (100 ha/989 images). This was done to reduce the size of the data to facilitate easier visualisation and analyses of the $3 \mathrm{D}$ products. The dense point cloud datasets were then directly used for mesh generation in order to have a surface with all the terrain features (DEM). The dense point clouds were then imported into PhotoScan again to complete the automatic division of all the points into two classes - ground and above ground (Figure 5). A dense point cloud with only ground and low points was obtained which was then exported as a digital terrain model (DTM). Mesh generation removed all aspects that are above ground such as the buildings and vegetation. The results were exported in various formats including point clouds (ASPRS LAS), orthophotos (GeoTIFF, Google Earth KMZ), DEMs and DTMs (GeoTIFF elevation) from classified point clouds. 


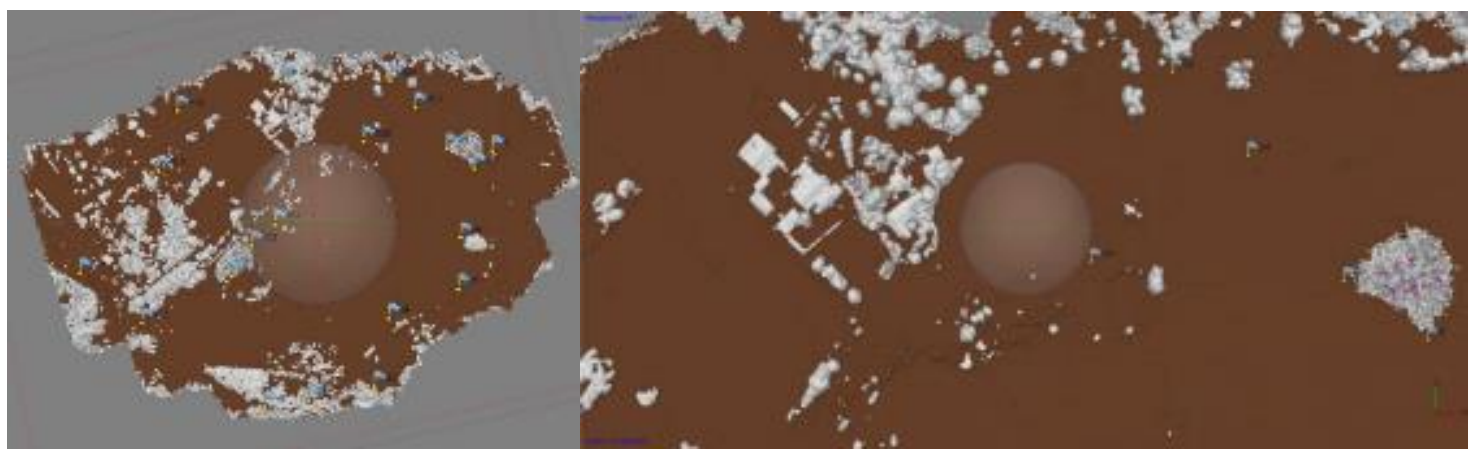

Figure 5.The automatic division of all the points into two classes - ground points (brown) and the rest (grey) was performed

An Intel Xeon CPU E5-1650 v3 work station with 32 GB of RAM, which required 36 hours of processing to complete the generation of the initial point cloud and export of the point cloud and initial orthophotos was used. The rest of the processing for the generation of the smaller spatial extent point cloud and the large spatial extent point cloud (low reconstruction) was completed on an Intel Core i5 -3210 CPU laptop with 6 GB of RAM.

\subsection{Editing, Data Classification and Interpretation}

The data quality (accuracy) and quantity was assessed for the images, orthophoto and 3D model generation trough automatic image quality estimation feature and accuracy report export (processing report) from PhotoScan (Agisoft LLC, 2014). The Quick Terrain Modeller 805 software model statistics function was further used to provide information on the specifications and precision. The surface models (DEMs and DTMs) and point clouds were edited using the edit mode of Quick Terrain Modeller (QTM) 805 (Applied Imagery, 2015). Areas within the point clouds and surface models that needed to be edited were selected for further removal of noise such as spikes (especially over large surfaces with water) and irregular points (points located outside spatial limits). The surface models (DEMs and DTMs) were also further clean up by cutting and smoothing any unnecessary surface areas located outside spatial limits. This quick and precise editing ensures that accurate analysis can be performed on these $3 \mathrm{D}$ models, for example accurate slope and profile analysis. The high resolution orthophotos were interpreted using the QGIS 2.2.0 application and Global Mapper v17 (Blue Marble Geographics, 2015) for the GeoTIFF and Google Earth was used for the KMZ formats. QTM was used as the key application/tool for interpretation of the UAV point clouds and surface models.

\section{Results and Discussion}

The UAV survey was completed within $2 \frac{1}{2}$ hours for the 100 ha study area. A total amount of 989 images was used for creating the initial point cloud which resulted in 861296939 points which required 36 hours of processing to complete the generation of the dense point cloud, 
export of the point cloud and initial 5 and $10 \mathrm{~cm}$ ground pixel resolution orthophotos (full study extent high reconstruction quality). The results of the geometric accuracy (Table 1) of the data based on the 20 GCPs were $0.018 \mathrm{~m}$ for the overall and $0.0025 \mathrm{~m}$ for the vertical RMSE. These results indicate accuracy greater than other SfM and UAV photogrammetry studies such as Hugenholtz et al., (2013) with a 0.18m vertical RMSE, (Dandois and Ellis, 2013) with a vertical RMSE up to $0.4 \mathrm{~m}$, Lucieer et al. (2014) with a $0.042 \mathrm{~m}$ overall RMSE and Ouédraogo et al., (2014) $0.09 \mathrm{~m}$ RMSE. The vertical accuracy achieved in this study can be prescribed due to amount of ground control used, the utilisation of a very stable multirotor UAV including the usage of PhotoScan which was extensively tested in the scientific field and for a variety of other applications. The point cloud heights corresponded with the heights of measured GCPs. Hugenholtz et al., (2013) also compared UAV RMSE with airborne LiDAR RMSE datasets and reported better accuracy for the former.

Table 1. Overall precision (m) of the UAV derived data based on the 20 GCPs

\begin{tabular}{|c|c|c|c|c|c|c|}
\hline Label & $\mathrm{X}$ error $(\mathbf{m})$ & Y error (m) & $Z$ error (m) & Error (m) & Projections & Error (pix) \\
\hline $\mathrm{X} 1$ & -0.002566 & -0.002265 & 0.001939 & 0.003934 & 8 & 0.136952 \\
\hline $\mathrm{X} 2$ & -0.013977 & -0.005127 & -0.002264 & 0.015058 & 13 & 0.112164 \\
\hline $\mathrm{X} 3$ & -0.000812 & 0.004812 & 0.001041 & 0.004989 & 15 & 0.122789 \\
\hline $\mathrm{X} 4$ & 0.000094 & 0.001160 & 0.001032 & 0.001556 & 12 & 0.162393 \\
\hline $\mathrm{X} 5$ & -0.017644 & 0.009968 & -0.000611 & 0.020274 & 18 & 0.171948 \\
\hline X6 & -0.013679 & -0.004910 & 0.001001 & 0.014568 & 8 & 0.267826 \\
\hline $\mathrm{X} 7$ & 0.003035 & 0.023995 & -0.000507 & 0.024191 & 11 & 0.201251 \\
\hline $\mathrm{X} 8$ & -0.016527 & 0.008790 & -0.002894 & 0.018942 & 9 & 0.205882 \\
\hline X9 & 0.030241 & -0.000631 & 0.005552 & 0.030753 & 8 & 0.237399 \\
\hline $\mathrm{X} 10$ & -0.010127 & -0.034330 & -0.000441 & 0.035795 & 7 & 0.258421 \\
\hline $\mathrm{X} 11$ & -0.008732 & 0.010492 & -0.003019 & 0.013980 & 5 & 0.104323 \\
\hline $\mathrm{X} 12$ & 0.005095 & 0.031798 & 0.004115 & 0.032465 & 8 & 0.069698 \\
\hline $\mathrm{X} 13$ & -0.002728 & -0.006585 & -0.000202 & 0.007131 & 16 & 0.244304 \\
\hline $\mathrm{X} 14$ & 0.001635 & -0.005543 & 0.000238 & 0.005784 & 7 & 0.068217 \\
\hline $\mathrm{X} 15$ & 0.001150 & -0.004463 & 0.001124 & 0.004744 & 7 & 0.093595 \\
\hline $\mathrm{X} 16$ & 0.008410 & -0.012559 & 0.001756 & 0.015217 & 8 & 0.149077 \\
\hline $\mathrm{X} 17$ & 0.014196 & -0.001467 & -0.000434 & 0.014278 & 17 & 0.203893 \\
\hline
\end{tabular}


South African Journal of Geomatics, Vol. 5. No. 2, September 2016

\begin{tabular}{|c|c|c|c|c|c|c|}
\hline Label & X error $(\mathbf{m})$ & Y error $(\mathbf{m})$ & Z error $(\mathbf{m})$ & Error $(\mathbf{m})$ & Projections & Error (pix) \\
\hline X18 & 0.019705 & -0.009310 & -0.001733 & 0.021862 & 9 & 0.190727 \\
\hline X19 & 0.013097 & -0.006749 & -0.005743 & 0.015814 & 8 & 0.108387 \\
\hline X20 & -0.009246 & 0.002520 & 0.003047 & 0.010056 & 16 & 0.160018 \\
\hline Total & $\mathbf{0 . 0 1 2 3 1 2}$ & $\mathbf{0 . 0 1 3 2 7 6}$ & $\mathbf{0 . 0 0 2 5 3 0}$ & $\mathbf{0 . 0 1 8 2 8 2}$ & $\mathbf{2 1 0}$ & $\mathbf{0 . 1 7 6 8 1 4}$ \\
\hline
\end{tabular}

The number of points for the smaller spatial extent point cloud (high reconstruction quality) resulted in 261427437 points and an average of $692.7 / \mathrm{m}^{2}$ point density. A summary of the model statistics of the smaller spatial extent point cloud (surface and ground points) that cover the wetland area is presented in Table 2.

Table 2. A summary of the model statistics of the point cloud for the wetland area

(Applied Imagery, 2015)

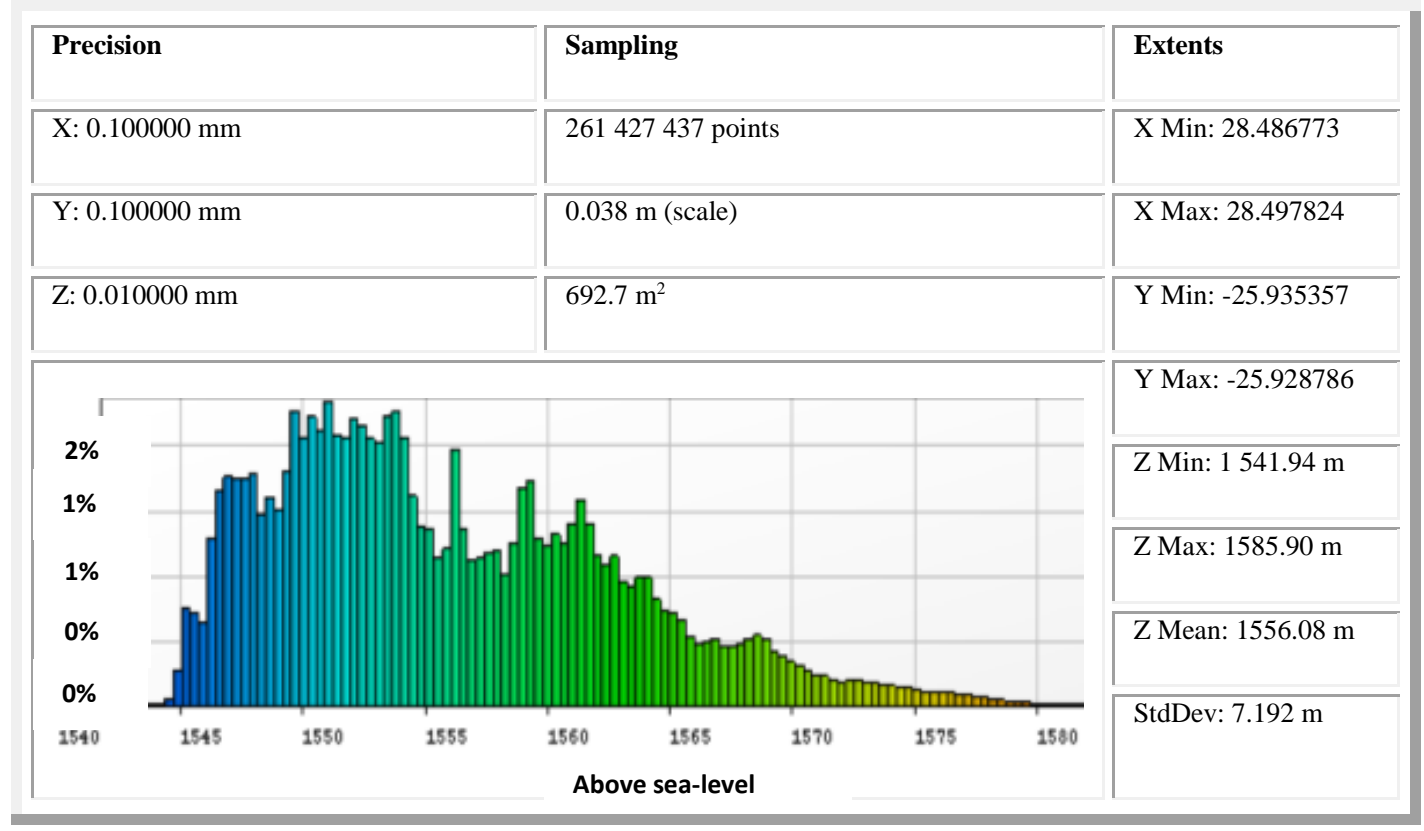

The number of points for the larger spatial extent point cloud (low reconstruction quality) resulted in 12489256 points and an average of $11.8 / \mathrm{m}^{2}$ point density. The results of the point density indicate that high point densities were obtained that enabled accurate detection (Fritz et $a l ., 2013$ ) and representation of features as is the case with LiDAR (Gillrich and Lichvar, 2014) although the UAV derived point densities is much greater than points derived from aerial laser scanning (Fritz et al., 2013). A $0.018 \mathrm{~m}$ and $0.025 \mathrm{~m}$ ground pixel resolution orthophoto and a $0.038 \mathrm{~m}$ point cloud and surface model (DEM and a DTM after classification) were derived from the smaller spatial extent point cloud and aerial photographs respectively (high reconstruction quality). A $0.29 \mathrm{~m}$ surface model (DEM and a DTM after classification) was derived from large extent data (low reconstruction quality). 
The interpretation of aerial photographs for wetland studies requires experience, some degree of familiarity with the area being covered, and preferably a certain amount of field verification of the interpretations made (Kotze, 2009). This also applies to point clouds or other related products (Gillrich and Lichvar, 2014). The available time and budgets allocated to wetland studies don't always allow for extensive studies being undertaken. Limited time is for example available for soil augering and determination and verification of hydrological features within the wetland. It is further important to understand how water flows through the landscape especially in a transformed landscape such as this particular study area where all the indicators are not visible, and one should look deeper into elements such as slope, detailed landscape profile and floodlines. It is exactly for these reasons that UAV products enhance wetland mapping. A slope/profile analysis was calculated for the wetland using the $0.29 \mathrm{~m} \mathrm{DTM}$ (Figure 6 ), resulting in a slope of $1.013^{\circ}$ or $1.77 \%$ compared to a minimum of $2.4 \%$ determined using the Google Earth elevation profile tool. The high spatial resolution and vertical accuracy we achieved made it possible to complete accurate measurements from the UAV point clouds and surface models. These measurements were confirmed through field verification. Even narrow features which are normally not accurately presented in light detection and ranging (LiDAR) data (Gillrich and Lichvar, 2014) for example small gullies, drains including possible obstructions, were represented accurately within the UAV derived point clouds and surface models (Figure 7). A limitation of UAV SfM photogrammetry though is that it is unable to reconstruct surfaces located underneath trees while LiDAR is capable of achieving this (James et al., 2007). There was a difficulty to reconstruct the larger water surfaces were the SfM algorithms do not found overlapping points mostly as a result of moving water which led to noise (irregular points) over the water surfaces. Although the noise was removed trough editing, the accuracy of the created surface may be lower than the rest of the surface model. The high resolution 3D view of the point clouds and surface models allows delineators/researchers to "see landscape scale patterns created by the locations of indicators relative to one another" (Gillrich and Lichvar, 2014, p.26). These products can and may not replace field studies but are an excellent tool if used in combination with field studies. Figure 8 indicates the initial $10 \mathrm{~cm}$ ground pixel resolution orthophoto derived from the point cloud for the 100ha study area. The accurate high resolution UAV orthophotos on itself provide wetland specialists the opportunity to identify features such as areas of water accumulation, detailed watercourse characteristics, identification of wetness gradient lines formed by hydrophilic vegetation and with some information from field studies one can identify hydrophilic vegetation extents and even identify certain wetland species including invasive plants. These high resolution UAV orthophotos further provide accurate information in terms of the extent and type of anthropogenic impacts. Figure 9 presents a zoomed in $2.5 \mathrm{~cm}$ ground pixel resolution orthophoto of the wetland where the deep flooding by an earthen dam can be identified including the extent be determined. The orthophoto further provided information such as the Kikuyu grass that has overgrown the earthen dam including the position of the drains within 
the wetland. The UAV orthophotos can further also be overlayed as a texture in combination with the DEMs within tools such as QTM to further enhance visual interpretation.
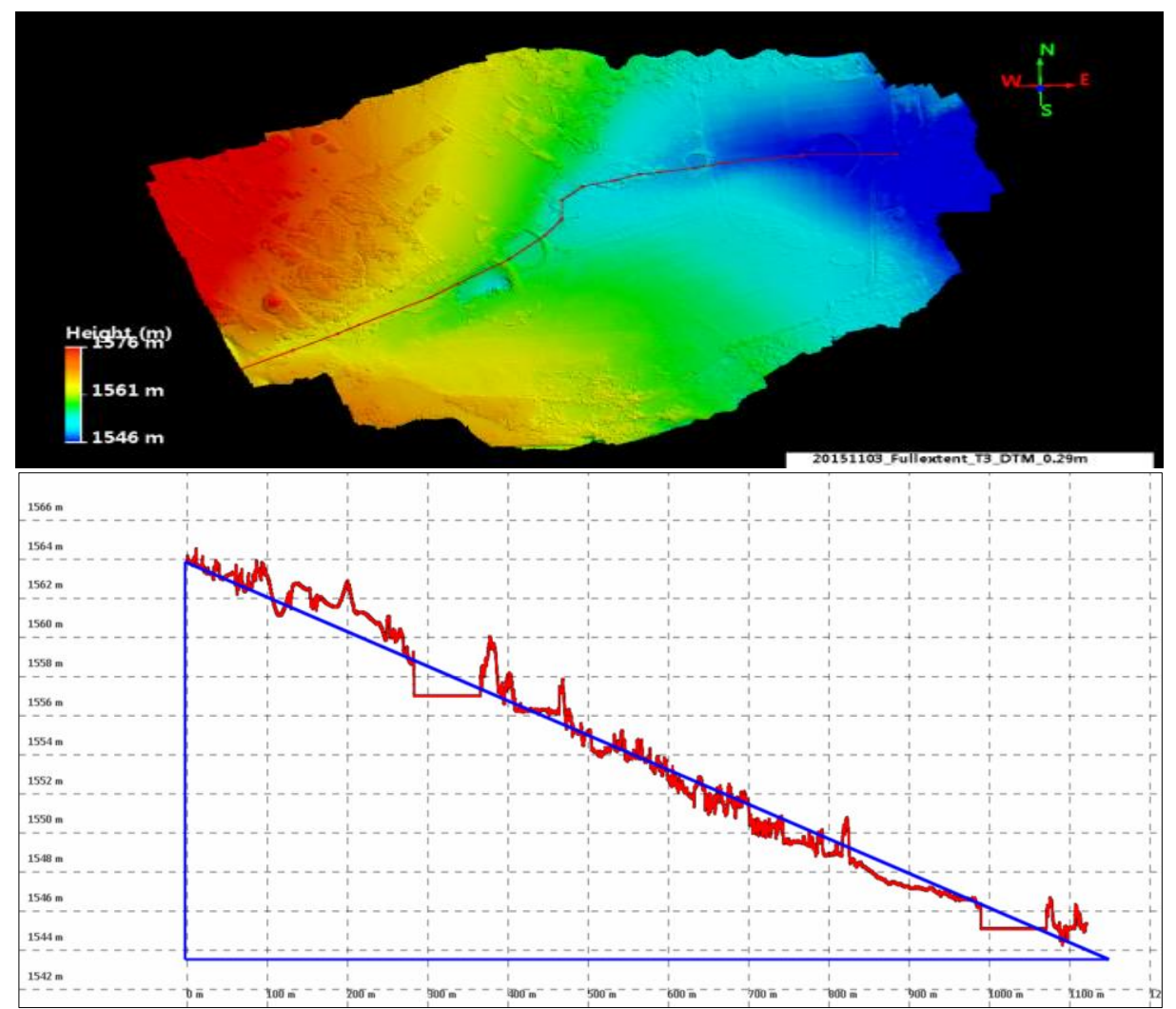

Figure 6. The average slope (profile analysis) calculated for the wetland is $1.77 \%$ (Applied Imagery, 2015)

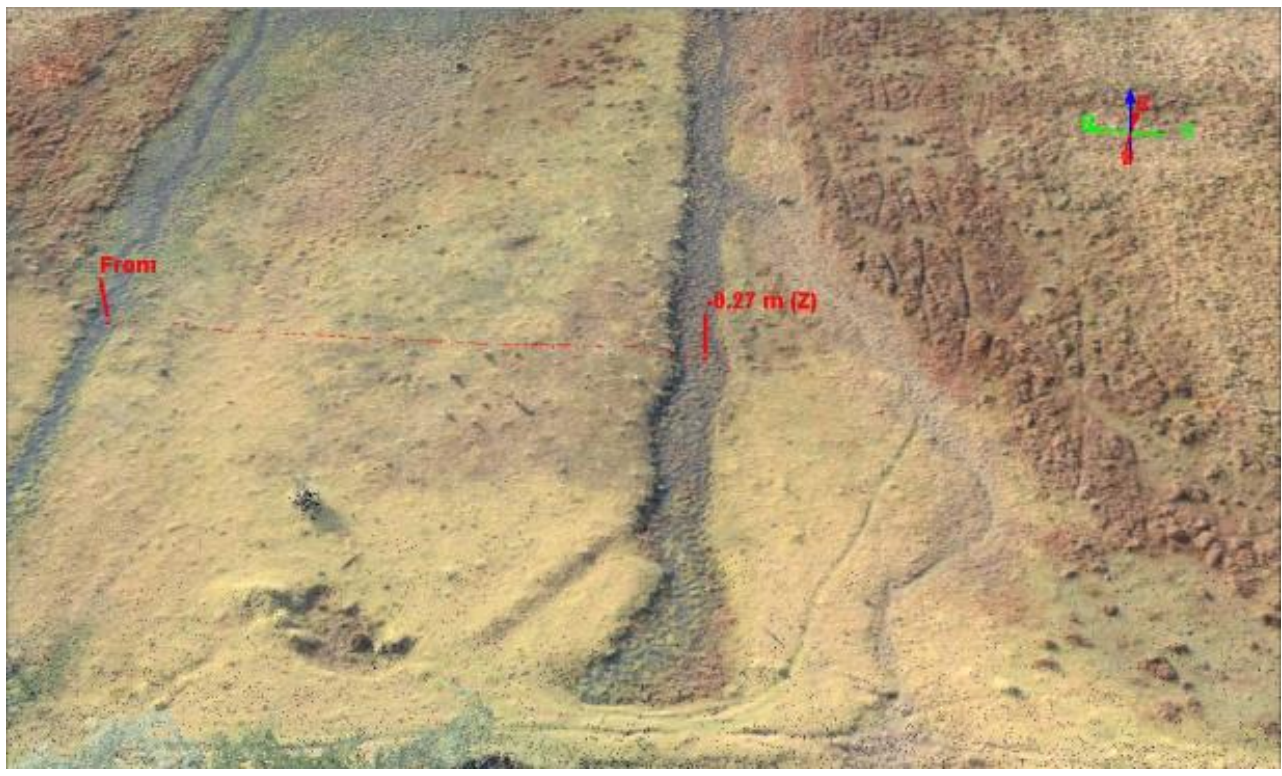

Figure 7 . The $0.38 \mathrm{~m} 3 \mathrm{D}$ dense point cloud allows accurate measurement of depth of drains within the wetland 


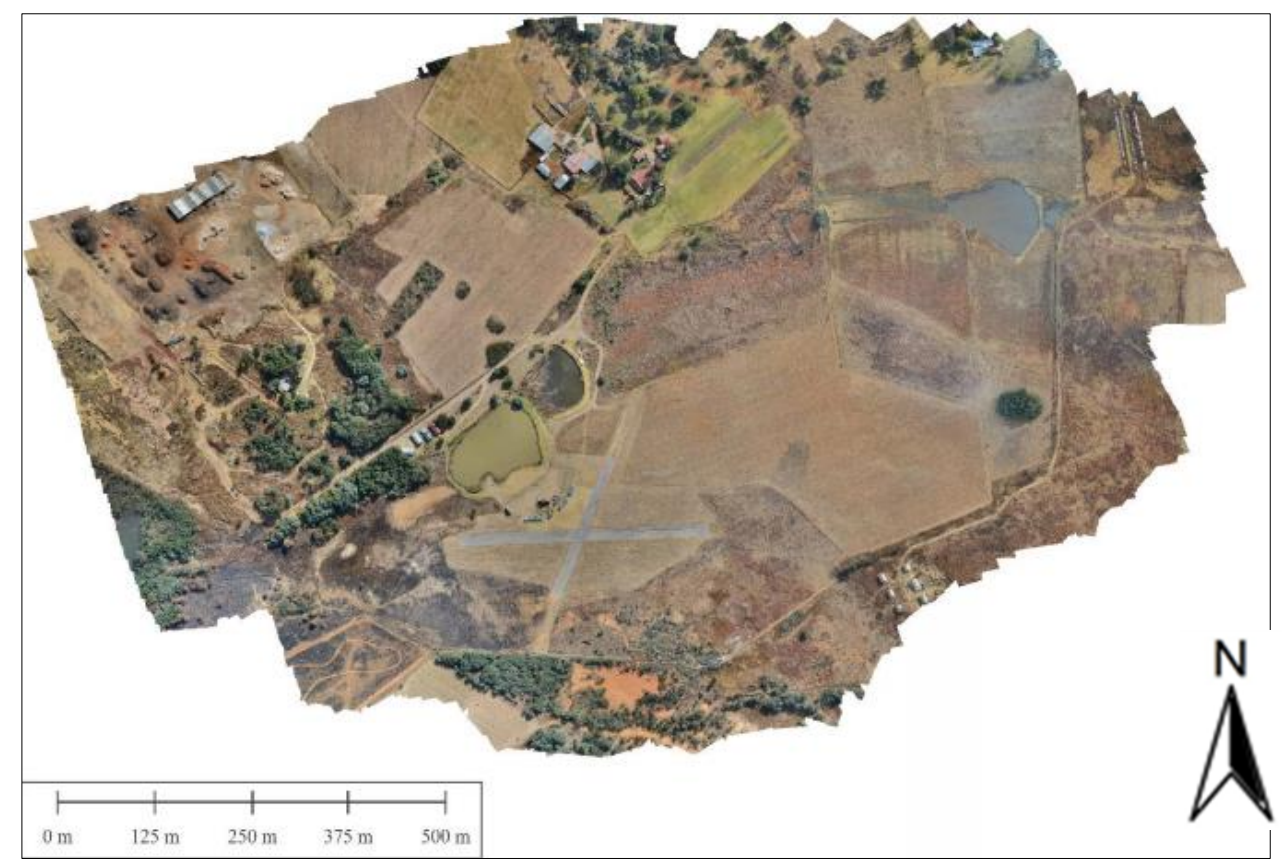

Figure 8 . A $10 \mathrm{~cm}$ ground pixel resolution orthophoto derived from the point cloud for the 100ha study area

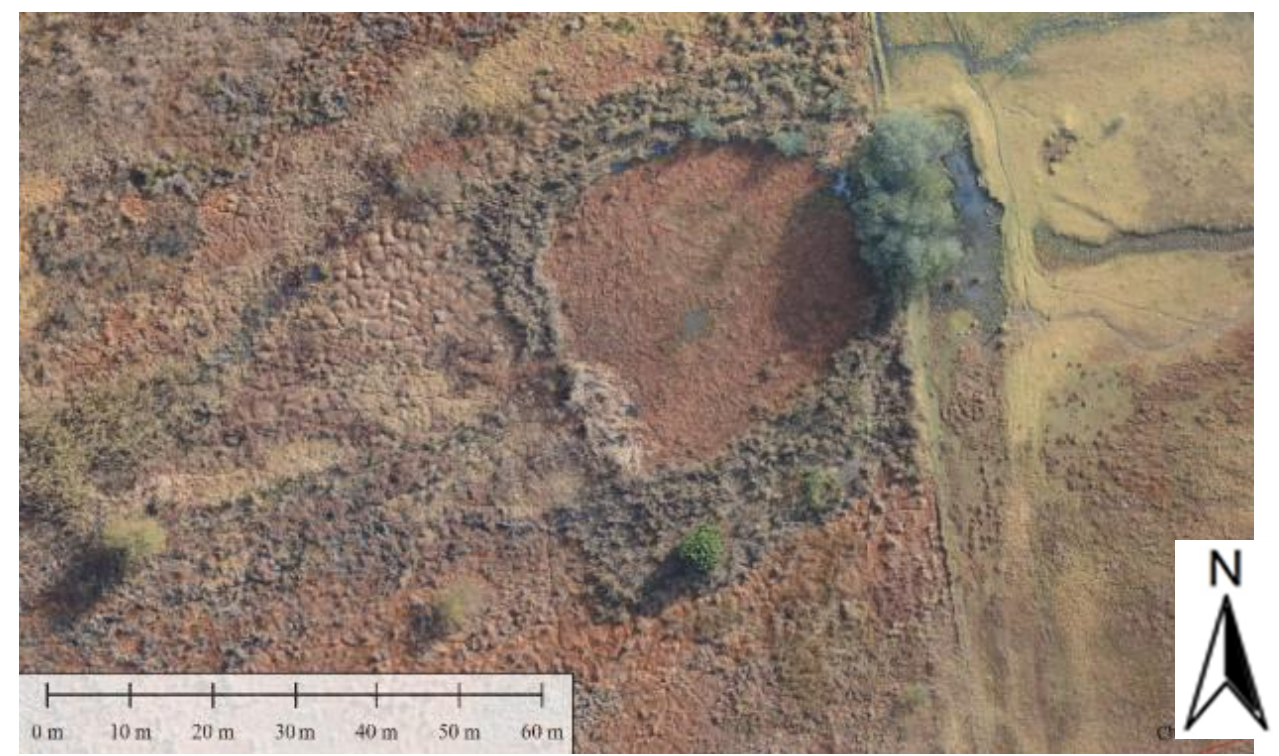

Figure 9. Identification and estimation of disturbances within the wetland using the $2.5 \mathrm{~cm}$ UAV orthophoto

\section{Conclusion}

The results suggest that UAV photogrammetry can significantly enhance wetland mapping and thereby enhance wetland studies and research. The UAV products which are inexpensive can be acquired relatively easily and in a short period of time with the recent technological advancements. The precision and quality of the UAV products is unparalleled comparing it to more conventional remote sensing using satellite imagery, which is mostly used for research in wetland ecosystems. The UAV data may provide the information for this gap. UAV 
photogrammetry may provide some of the much needed answers for hydrological and geomorphological questions and for detecting even small changes trough repetitive surveys and thereby be a tool used to do precision monitoring and planning of wetland rehabilitation interventions.

Some of the limitations of the study include that we did not use independent GCPs for verification of the positional and height accuracy. This will be added in future studies. A hydro survey using a small unmanned Hydrobot can be added in future to enable accurate representation of the earthen dam's bathymetry. This data can then be merged with the UAV data.

\section{Acknowledgements}

We would like to thank Aerial Kopter Solutions (AKS) and the RPAS Training Academy (PTY) Ltd who provided the equipment, resources and expertise to complete the surveying for this project. University of Johannesburg (UJ) Department of Geography, Environmental Management and Energy Studies for the use of their computer to process this large dataset and the UJ Zoology Department that made it possible to undertake this research.

\section{References}

Agisoft LLC, 2014. Agisoft PhotoScan User Manual Professional Edition, Version 1.1, viewed 25 February 2015, <http://www.agisoft.com/pdf/PhotoScan-pro_1_1_en.pdf>.

Ahmad, A, Tahar, K, Udin, W, Hashim, K, Darwin, N, Room, M, Hamid, N, Azhar, N, Azmi, S 2013, 'Digital Aerial Imagery of Unmanned Aerial Vehicle for Various Applications' . Computing and Engineering, IEEE International Conference on Control System, Penang Malaysia, 2013, pp. 535-540.

Anderson, K and Gaston, KJ 2013. 'Lightweight unmanned aerial vehicles will revolutionize spatial ecology'. Frontiers in Ecology and the Environment, vol. 11, no.3, pp. 138-146.

Applied Imagery, 2015. Quick Terrain Modeller 8.0.5. Silver Spring, MD: Johns Hopkins Applied Physics Laboratory.

Blue Marble Geographics, 2015. Global Mapper v17. 77 Water Street, Hallowell, Maine 04347 USA

Colomina, I and Molina, P 2014, 'Unmanned aerial systems for photogrammetry and remote sensing: A review'. ISPRS Journal of Photogrammetry and Remote Sensing, vol. 92, pp. 79-97.

Dandois, JP and Ellis, EC 2013, 'High spatial resolution three-dimensional mapping of vegetation spectral dynamics using computer vision'. Remote Sensing of Environment. vol. 136, pp. 259-276.

Ellery, W, Grenfell, M, Grenfell, S, Kotze, D., McCarrthy, T, Tooth, S, Grundling, P., Beckedahl, H., Le 
Maitre, D., and Ramsay, L 2009, Wet-Origins: Controls on the distribution and dynamics of wetlands in South Africa. Water Research Commission, Pretoria. WRC Report No TT 334/09

Flener, C, Vaaja, M, Jaakkola, A, Krooks, A, Kaatinen, H, KukKo, A, Kasvi, E., Hyyppa, H, Hyyppa, J and Alho, P 2013, 'Seamless Mapping of River Channels at High Resolution Using Mobile LiDAR and UAV-Photography'. Remote Sens. vol. 5, pp. 6382-6407.

Fonstad, M, Dietrich, J, Coourville, B, Jensen, J, and Carbonneau, P 2013, 'Topographic structure from motion: a new development in photogrammetric measurement'. Earth Surface Processes and Landforms, vol. 38, pp. 421-430.

Fritz A, Kattenborn T and Koch B 2013, 'UAV-Based Photogrammetric Point Clouds - Tree Stem Mapping in Open Stands in Comparison to Terrestrial Laser Scanner Point Clouds International'. Archives of the Photogrammetry, Remote Sensing and Spatial Information Sciences, Volume XL1/W2, 2013 UAV-g2013, Rockstock, Germany, 4-6 September 2013, pp. 141-146.

Gillrich, J and Lichvar, R 2014, Use of LiDAR to Assist in Delineating Waters of the United States, Including Wetlands. US Army Corps of Engineers Cold Regions Research and Engineering Laboratory. ERDC/CRREL TR-14-3, viewed 25 September 2015, $<$ http://acwc.sdp.sirsi.net/client/en_US/search/asset/1034040;jsessionid=7FF186ECABF87EB128596 51E215E8B30.enterprise-15000>.

Gonçalves, JA and Hernriques, R 2015, 'UAV photogrammetry for topographic monitoring of coastal areas'. ISPRS Journal of Photogrammetry and Remote Sensing, vol. 104, pp. 101-111.

Hugenholtz, CH, Whitehead, K, Brown, OW, Barchyn, TE, Moorman, BJ, LeCliar, A, Riddell, K and Hamilton, T 2013, 'Geomorphological mapping with a small unmanned aircraft system (sUAS): Feature detection and accuracy assessment of a photogram metrically-derived terrain model' . Geomorphology, vol. 194, pp. 16-24.

James, L, Watson, D and Hansen, W 2007, 'Using LiDAR data to map gullies and headwater streams under forest canopy: South Carolina, USA'. Catena, vol. 71, pp.132-144.

James, R and Robson, S 2012, 'Straight forward reconstruction of 3D surfaces and topography with a camera: accuracy and geoscience application '. Journal of Geophysical Research, vol.117, pp. 1-17.

Kotze D, Marneweck G, Batchelor A, Lindley D and Collins N 2009, Wet-Ecoservices: A technique for rapidly assessing ecosystem services supplied by wetlands. Water Research Commission, Pretoria. WRC Report No TT 339/09

Lechner, A, Fletcher, A, Johansen, K and Erskine, P 2012, 'Characterising Upland Swamps Using Object-Based Classification Methods and Hyper-Spatial Resolution Imagery Derived from An Unmanned Aerial Vehicle'. ISPRS Annals of the Photogrammetry, Remote Sensing and Spatial Information Sciences, Melbourne, Australia vol. 1-4, pp. 101-106.

Li, N, Zhou, D, Duan, Z, Wang, S and Cui, Y 2010, 'Application of unmanned airship image system and processing techniques for identifying of fresh water wetlands at a community scale'. In: Proceedings of IEEE 18th Geoinformatics International Conference. Beijing: IEEE. 
Lucieer, A, Turner, D, King, D and Robinson, S 2013, 'Using an Unmanned Aerial Vehicle (UAV) to capture micro-topography of Antarctic moss beds'. International Journal of Applied Earth Observation and Geoinformation, vol. 27, pp. 53-62.

Marcaccio, J, Markle, C and Chow-Fraser, P 2015, 'Unmanned aerial vehicles produces high-resolution, seasonally-relevant imagery for classifying wetland vegetation'. International Archives of the Photogrammetry, Remote Sensing and Spatial Information Sciences, Toronto, Canada, vol. XL-1/W4, pp. 249-256.

Ouédraogo, M, Degré, A, Debouche, C and Lisein, J 2014, 'The evaluation of unmanned aerial systembased photogrammetry and terrestrial laser scanning to generate DEMs of agricultural watersheds'. Geomorphology, vol. 214, pp. 229-355.

Peterman, V and Mesarič, M 2012, 'Land Survey from Unmanned Aerial Vehicle'. International Archives of the Photogrammetry, Remote Sensing and Spatial Information Sciences, Melbourne, Australia, vol. XXXIX-B1,pp. 447-451.

Rathinam, S, Almeida, S, Kim, Z, Jackson, S, Tinka, A, Grossman, W, and Sengupta, R 2007, 'Autonomous Searching and Tracking of a River Using an UAV'. In: Proceedings of American Control Conference, New York: IEEE, pp. 359-364.

Shahbazi, M, Théau, J and Ménard, P 2014, 'Recent applications of unmanned aerial imagery in natural resource management'. GIScience \& Remote Sensing, pp. 1-27.

Stöcker, C, Eltner, A and Karrasch, P 2015, 'Measuring gullies by synergetic application of UAV and close range photogrammetry - A case study from Andalusia, Spain'. Catena, vol. 132, pp.1-11.

Thamm, HP, Menz, G, Becker, M, Kuria, DN, Misana, S and Kohn, D 2013, 'The Use of UAS for Assessing Agricultural Systems in an Wetland in Tanzania in the Dry- and Wet-season for Sustainable Agriculture and Providing Ground Truth for TERRA-SAR X Data'. Archives of the Photogrammetry, Remote Sensing and Spatial Information Sciences, Rockstock, Germany Vol. XL-1/W2, 2013 UAVg2013, pp. 401-406.

van Blyenburgh, P 2013, 2013-2014 RPAS Yearbook: Remotely Piloted Aircraft Systems: The Global Perspective 2013/2014. Technical Report. UVS International. Paris, France.

Verhoeven, G 2011, 'Taking computer vision aloft archaeological three dimensional reconstructions from aerial photographs with PhotoScan'. Archaeological Prospection, vol. 18, pp. 67-73.

Westoby, M, Brasingon, J, Glasser, N, Hambrey, M, and Reynolds, J 2012, ' Structure fromMotion'photogrammetry: a low-cost, effective tool for geoscience applications'. Geomorphology, vol. 179 , pp. 300-314.

Zweig, CL, Burgess, MA, Pecival, HF, and Kitchens, WM 2015, 'Use of Unmanned Aircraft Systems to Delineate Fine-Scale Wetland Vegetation Communities'. Wetlands, vol. 35, pp.303-309. 